\title{
Development of a loop-mediated isothermal amplification assay for the rapid detection of six common respiratory viruses
}

\author{
Nianzhen Chen ${ }^{1} \cdot$ Yuying $\mathrm{Si}^{1} \cdot$ Gen $\mathrm{Li}^{1} \cdot$ Ming Zong ${ }^{1} \cdot$ Wenyan Zhang ${ }^{1} \cdot$ Yangqin $\mathrm{Ye}^{1} \cdot$ Lieying Fan $^{1} \mathbb{C}$
}

Received: 6 May 2021 / Accepted: 23 June 2021 / Published online: 15 July 2021

(c) The Author(s), under exclusive licence to Springer-Verlag GmbH Germany, part of Springer Nature 2021

\begin{abstract}
Due to the highly contagious and spreads quickly of respiratory infectious diseases (ADR), the availability of rapid, sensitive, and reliable diagnostic methods is essential for disease control. Here, we develop an approach based on loop-mediated isothermal amplification (LAMP) for the detection of influenza A virus (Flu A), Flu A subtypes H1N1and H3N2, influenza B virus (Flu B), respiratory syncytial virus (RSV) subtypes A and B, human adenovirus (HAdV), parainfluenza virus (PIV) subtypes 1 and 3, and human rhinovirus (HRV) simultaneously. We designed primers specific to detect respiratory viruses above, optimized the RT-LAMP assay and evaluated it for its sensitivity and specificity of detection using real-time monitoring based on SYBR Green I. We also evaluated the result of our RT-LAMP assay on 638 nasopharyngeal swab specimens with the commercial RT-PCR by Cohen's Kappa. The inconsistent results were verified by Sanger sequencing furtherly. The developed RT-LAMP assay displayed a detection limit of $1 \times 10^{2}$ copies/ml RNA close to that of RT-PCR; no cross-reactivity was observed in the 10 kinds of viruses studied. The results obtained with 638 clinical samples indicate that the developed method has high specificity $(0.988-1)$ and sensitivity $(0.863-1)$ for viruses studied, and the Kappa value of all viruses was more than 0.85 revealed an excellent agreement between the two methods. We developed an RT-LAMP-based method and optimized for the detection of common respiratory viruses. It may be a powerful tool for rapid and reliable clinical diagnosis of ADR in primary hospitals.
\end{abstract}

Keywords Respiratory infectious diseases $\cdot$ Virus $\cdot$ RT-LAMP $\cdot$ Rapid detection

\section{Introduction}

Compared to other diseases, respiratory infectious diseases which are highly contagious and spreads quickly, contribute significantly to morbidity and mortality $[1,2]$. Upper respiratory tract infection (URTI) is one of the most common infectious; approximately $80-90 \%$ are caused by virus infection [3]. These viruses primarily include influenza $A$ virus (Flu A), influenza B virus (Flu B), respiratory syncytial virus (RSV), human adenovirus (HAdV), parainfluenza virus (PIV), and human rhinovirus (HRV) [3, 4]. Besides,

Nianzhen Chen, Yuying Si, and Gen Li contributed equally to this work.

\section{Lieying Fan}

flieying@yeah.net

1 Department of Clinical Laboratory, Shanghai

East Hospital, 150 Ji Mo Road, Shanghai 200120,

People's Republic of China the outbreak of severe acute respiratory syndrome coronavirus 2 (SARS-CoV-2) infection has become a global epidemic threat since the end of 2019 [5].

As we all know, influenza tends to spread rapidly in seasonal epidemics and presents diverse clinical manifestations, ranging in severity from self-limiting URTI to severe or even life-threatening lower respiratory tract infections (LRTI). Consequently, outpatient and emergency departments often experience a dramatic increase in the number of patients. However, conventional detection methods for diagnosing respiratory virus infections, such as virus isolation and serological, are unable to meet the demand for rapid diagnosis. In recent years, molecular diagnostic methods, especially the polymerase chain reaction (PCR) technology, are widely used to detect respiratory viruses for their high amplification efficiency [6,7], compensating for the deficiency of traditional diagnostic methods. But most of them are based on real-time PCR which is not convenient for basic laboratories and community hospitals for the requirement of thermal cycler with real-time fluorescence measurement, 
strict experimental operation condition, highly trained personnel, and time-consuming. Accordingly, it is necessary to establish fast, simple, and sensitive methods that apply to point-of-care testing (POCT) to facilitate the detection of URTI. The purpose of this paper is therefore to develop an approach for detecting viruses of URTI which not only saves time and cost but also has the potential to adapting POCT.

The loop-mediated isothermal amplification (LAMP) technology was established by Notomi et al. in 2000 [8], which rapidly amplifies DNA or RNA targets under isothermal conditions. LAMP could be performed with less sophisticated equipment such as a water bath and an ultraviolet lamp [9]; thus, it is suitable for rapid and simple diagnosis within poorly equipped primary hospitals and laboratories and in situations where an urgent diagnosis is needed. Briefly, it is a technology combine simple, rapid (within $45 \mathrm{~min}$ ), low-cost detection technique with high sensitivity and specificity [10].

In this study, we applied to develop novel reverse transcription LAMP (RT-LAMP) assays for the rapid and sensitive detection of main viral RNA among URTI, including Flu A, Flu B, RSV, HAdV, PIV, and HRV. We also evaluated the sensitivity and specificity of this assay. Furthermore, 638 clinical samples collected from patients were analyzed for clinical diagnosis.

\section{Materials and methods}

\section{Clinical specimens and ethics statement}

Totally, 638 nasopharyngeal (NP) swab specimens collected from pediatric patients were signs and symptoms of respiratory infection at Shanghai East Hospital, School of Medicine, Tongji University, between the winter of 2019 and 2020. There were 334 male and 304 female patients (male:female $=1.09: 1$ ). Ages were ranged from newborns to 17 years. All the samples were residual specimens after diagnostic sampling. Samples were collected in $1.5 \mathrm{ml}$ of transport medium and stored at $-80{ }^{\circ} \mathrm{C}$ in $500 \mu \mathrm{L}$ aliquots.

\section{Design of RT-LAMP primers}

The RT-LAMP primers were designed for ten viruses based upon sequences deposited in GenBank. We aligned the sequences using MEGA v.7.0 (http://www.megasoftwa re.net/) and confirmed the conservation of the selected sequence. To identify the most efficient primer set, five sets of specific RT-LAMP primers were initially designed using the online software Primer Explorer V5 (Eiken Chemical Co., Ltd., Tokyo, Japan; http://primerexplorer.jp/lampv5e/ index.html). Primer sets included an outer forward primer (F3), an outer backward primer (B3), a forward inner primer
(FIP), and a backward inner primer (BIP). A loop forward primer (LF) and/or a loop backward primer (LB) were also designed to accelerate the reaction. The detailed information regarding all the designed primer sets is shown in Table S1 (Supplementary Table S1). All primer pairs were synthesized by Sangon (Sangon Biotech Co., Ltd., Shanghai, China). The primers were formulated into a solution containing with $0.2 \mu \mathrm{M}$ of outer primers (F3 and B3), $1.6 \mu \mathrm{M}$ of inner primers (FIP and BIP), and $0.6 \mu \mathrm{M}$ of loop primers (LF and LB) and stored at $-20{ }^{\circ} \mathrm{C}$.

\section{The RT-LAMP assay was established and optimized}

A $20 \mu \mathrm{L}$ RT-LAMP reaction system was set up, containing $2 \mu \mathrm{L}$ 10X ThermoPol Reaction Buffer, 1.0 $\mu \mathrm{L}$ enzyme mix (a mix of Bst 2.0 DNA polymerase and AMV reverse transcriptase), $10 \mu \mathrm{L}$ mixture (with $\mathrm{ddH}_{2} \mathrm{O}, \mathrm{Mg}^{2+}$ ), $1 \mu \mathrm{L}$ SYBR Green I (Beijing Solarbio Science \& Technology Co., Ltd., Beijing, China), and $1 \mu \mathrm{L}$ primer; $5 \mu \mathrm{L}$ of RNA template was added into each RT-LAMP reaction. The reaction was performed by the LightCycler480 (Roche Diagnostics) for real-time monitoring.

The reaction contained $10^{6}$ copies $/ \mathrm{ml}$ Influenza B virus standard strains as a template, purified water $\left(\mathrm{ddH}_{2} \mathrm{O}\right)$ served as a negative control and performed at four different temperatures $\left(59,61,63\right.$, or $\left.65^{\circ} \mathrm{C}\right)$ for $45 \mathrm{~min}$, and results were analyzed based on amplification curves. Every experiment was repeated three times. Based on the optimum reaction temperature, different magnesium ion $\left(\mathrm{Mg}^{2+}\right)$ concentrations $(4,6,8,10$, or $12 \mathrm{mM})$ were simultaneously optimized. Every experiment was repeated three times.

\section{Evaluation of the specificity and sensitivity of the RT-LAMP assay}

To evaluate the specificity of the RT-LAMP assay among Flu A, Flu B, RSV, HAdV, PIV, and HRV, standard strains were purchased from Shanghai Beinuo Biotechnology Co., Ltd., including Influenza A virus H1N1 (ATCC VR-1736) and H3N2 (ATCC VR-1811); Influenza B virus (ATCC VR-1735); RSV A (ATCC VR-1540) and B (ATCC VR-955); HAdV (ATCC VR-3), PIV1 (ATCC VR-94), and PIV3 (ATCC VR-93); and HRV (ATCC VR-1559, VR-284, VR-1600, and VR-1645). The RT-LAMP was cross-tested among the standard strains described above respectively, and every experiment was repeated three times.

To detect the sensitivity of the RT-LAMP assay, the copy number of the RNA standard was calculated using the following formula: copies $/ \mathrm{ml}=6.02 \times 10^{23} \times[$ RNA concentration $(\mathrm{g} / \mathrm{L}) /$ (fragment length $\times 340)$ ]. Viral RNA as described above was ten-fold serially diluted, ranging from $1 \times 10^{6}$ copies $/ \mathrm{ml}$ to $1 \times 10^{2}$ copies $/ \mathrm{ml}$. The serially diluted RNA was added to the RT-LAMP assay as described previously to 
test the sensitivity of the RT-LAMP assay. Every experiment was repeated three times.

\section{Evaluation of the RT-LAMP assay using clinical samples}

Total viral RNA was extracted from $200-\mu$ L throat swabs of 638 suspected respiratory tract infection patients, using an RNA extraction kit (Fosun Pharmaceutical Co., Ltd., Shanghai, China), according to the manufacturer's instructions. Purified nucleic acid $(40 \mu \mathrm{L})$ was frozen at $-80{ }^{\circ} \mathrm{C}$ in $5-\mu \mathrm{L}$ aliquots and then tested with the RT-LAMP assay, $\mathrm{ddH}_{2} \mathrm{O}$ was used as negative control, and the standard strain was used as the positive control. All the RT-LAMP assays were performed by the LightCycler480 (Roche Diagnostics) for real-time monitoring.

\section{Results were compared between the RT-LAMP and other methods}

Commercial real-time fluorescence reverse transcriptase polymerase chain reaction (RT-PCR) kits were used as the reference standard for the RT-LAMP to detect the proviruses, respectively, including detection kit for discrimination of Influenza A and B Viruses (Shanghai ZJ Bio-Tech Co., Ltd.); simultaneous detection and distinction of human respiratory syncytial virus A and B kit (Shanghai ZJ BioTech Co., Ltd.); human adenovirus nucleic acid detection kit (Guangdong Hecin Scientific Co., Ltd.); human parainfluenza virus 1 nucleic acid detection kit (Guangdong Hecin Scientific Co., Ltd.); human parainfluenza virus 3 nucleic acid detection kit (Guangdong Hecin Scientific Co., Ltd.); and human rhinovirus nucleic acid detection kit (Hubei Land Medical Co., Ltd.). All of the reactions were set up according to the manufacturer's protocol.

Additionally, 518 of the $638 \mathrm{NP}$ samples had been tested using a commercial Colloidal Gold kit (Alere Bioengineering Co., Ltd., Hangzhou, China) to detect Flu A and B antigens. This is a simple qualitative assessment of influenza virus $A$ and $B$ antigens expression from NP swab specimens simultaneously, which depending on the use of monoclonal antibodies against Flu A and B conjugated with colloid gold.

\section{DNA sequencing}

Sanger sequencing was performed for the purpose of assisting in the resolution of discordant results between LAMP assay and RT-PCR. A $20 \mu \mathrm{L}$ of sample RNA was sent to Shanghai Biotech Bioengineering. The RNA was first amplified by nested PCR, and the purified products were sequenced by the methods of Sanger dideoxy. Designed nested PCR primers were based on the target gene (Supplementary Table S2), and target products mixing with a limited amount of dideoxy nucleotide triphosphate (ddNTP) without 3 '-OH during the amplification process produced four different lengths of nucleotides ending with A, T, C, and $\mathrm{G}$ and then were detected by electrophoresis on PAGE gel to obtain the DNA base sequence.

\section{Data processing and analysis}

To evaluating of the RT-LAMP assays in comparison with other methods as described above. The SPSS version 20.0 and GraphPad Prism 8.0 were used for data processing and analysis. Every viral detection result was analyzed using diagnostic test evaluation indexes, such as the specificity, the sensitivity, and the Cohen's kappa coefficient $(\kappa)$ with a 95\% CI. The strength of agreement was as follows: $\kappa<0.40$, poor agreement; $0.40 \leq \kappa<0.75$, fair to a good agreement; and $0.75 \leq \kappa<1.00$, excellent agreement.

\section{Results}

\section{Optimizing the RT-LAMP assay}

To screen for the optimum temperature, the reaction was incubated at four different temperatures $(59,61,63$, or $65^{\circ} \mathrm{C}$ ) for $45 \mathrm{~min}$. As presented in Fig. 1, the highest amplification efficiency occurred at $63{ }^{\circ} \mathrm{C}$. Thus, $63{ }^{\circ} \mathrm{C}$ was confirmed as the optimum temperature for the RT-LAMP assay.

The optimization of magnesium ion $\left(\mathrm{Mg}^{2+}\right)$ concentrations is essential for the RT-LAMP method. Based on the optimum reaction temperature, different $\mathrm{Mg}^{2+}$ concentrations $(4,6,8$, or $10 \mathrm{mM})$ were simultaneously optimized. As shown in Fig. 2, the highest amplification results were obtained at $8 \mathrm{mM}$. Also, it was observed that when $\mathrm{Mg}^{2+}$ concentrations elevated to $10 \mathrm{mM}$ will lead to false-positive results, and even could not amplify at all when it up to $12 \mathrm{mM}$. Thus, $8 \mathrm{mM}$ was deemed as the optimal $\mathrm{Mg}^{2+}$ concentration.

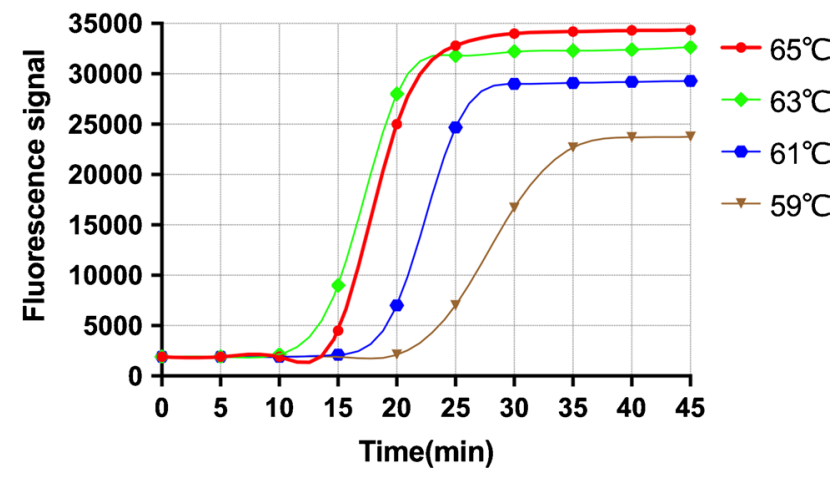

Fig. 1 Optimization of temperature. The reaction was incubated at four different temperatures $\left(59,61,63\right.$, or $\left.65^{\circ} \mathrm{C}\right)$ for $45 \mathrm{~min}$ 


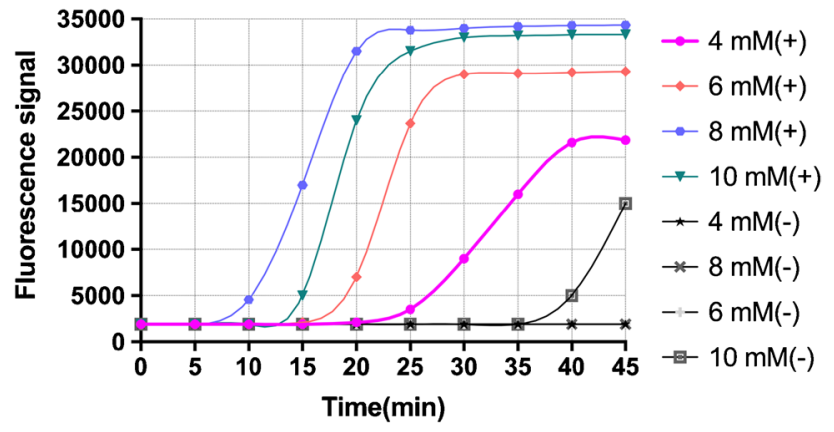

Fig. 2 Optimization of $\mathrm{Mg}^{2+}$. Concentration of $\mathrm{Mg}^{2+}$ in the positive system were $4 \mathrm{mM}(+), 6 \mathrm{mM}(+), 8 \mathrm{mM}(+)$, and $10 \mathrm{mM}(+)$, and concentration of $\mathrm{Mg}^{2+}$ in the negative system were $4 \mathrm{mM}(-), 6 \mathrm{mM}$ $(-), 8 \mathrm{mM}(-)$, and $10 \mathrm{mM}(-)$
Therefore, all subsequent RT-LAMP reactions were performed at $63{ }^{\circ} \mathrm{C}$ for $45 \mathrm{~min}$ by the LightCycler480 (Roche Diagnostics) for real-time monitoring.

\section{Specificity of the RT-LAMP assay}

The specificity of primers is essential for accurate detection of the RT-LAMP method. We had examined the specificity of the 10 developed RT-LAMP assays among Flu A, Flu B, RSV, HAdV, PIV, and HRV. As shown in Fig. 3, when the corresponding standard strains' RNA was added, only the corresponding well had an amplification curve, and the others showed no signal. Briefly, no cross-reactivity was observed in the RT-LAMP, indicating that the 10 developed RT-LAMP assays had high specificity for each of the 10 kinds of viruses studied.
A

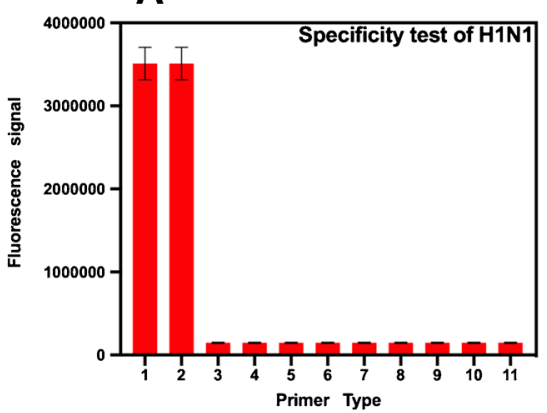

D

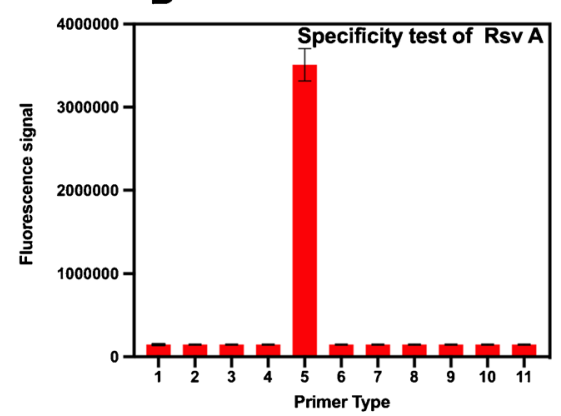

G

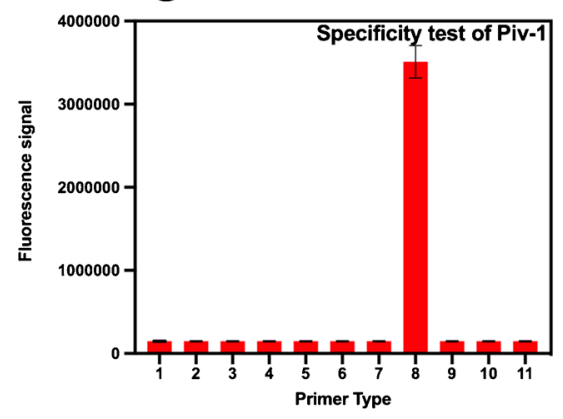

B

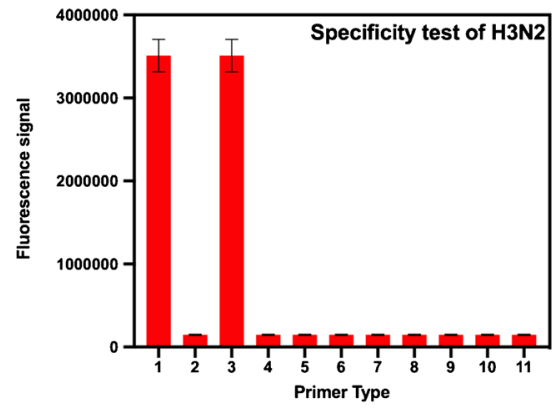

E

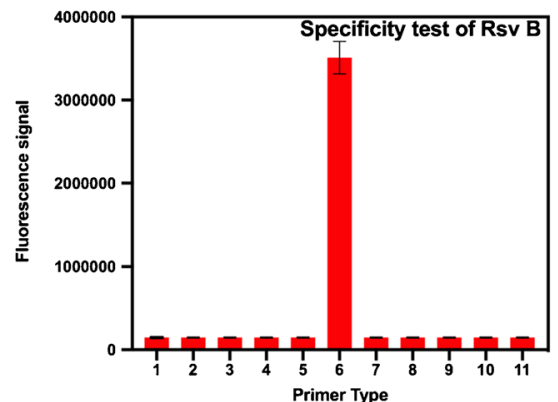

H

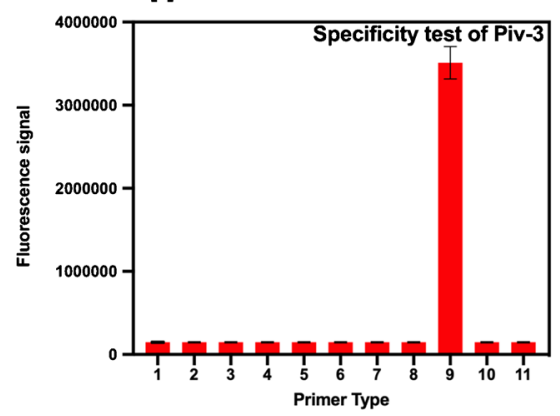

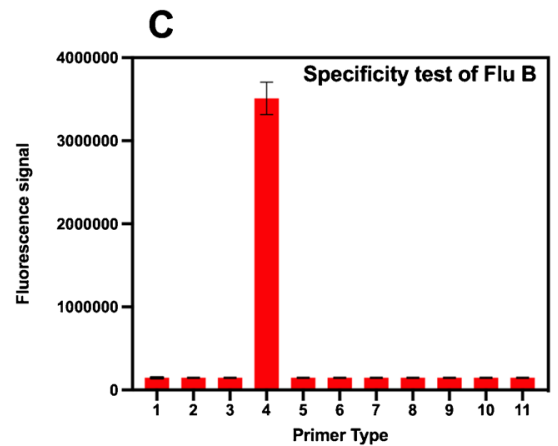
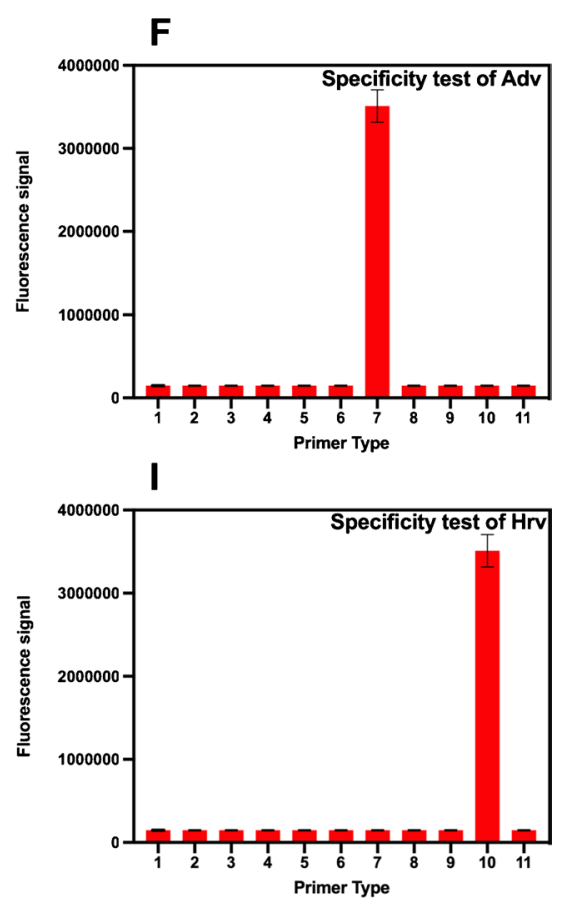

Fig. 3 Results of the specific evaluation of the different viral samples by different primers. Abscissa: 1, Flu A primer; 2, H1N1 primer; 3, H3N2 primer; 4, Flu B primer; 5, RSV A primer; 6, RSV B primer; 7,
HAdv primer; 8, PIV1 primer; 9, PIV3 primer; 10, HRV primer; 11, negative control 


\section{Sensitivity test for the RT-LAMP assay}

To ascertain the sensitivity of the 10 developed RT-LAMP assays, viral RNA as described above were ten-fold serially diluted, ranging from $1 \times 10^{6}$ copies $/ \mathrm{ml}$ to $1 \times 10^{1}$ copies $/ \mathrm{ml}$. The serially diluted RNA was added to the developed RTLAMP assay, respectively; as illustrated in Fig. 4, the time required for detection gradually increased with decreasing target concentrations, and all amplification curves appeared within $30 \mathrm{~min}$. These results indicated that the 10 developed RT-LAMP assays limit of detection was $1 \times 10^{2}$ copies $/ \mathrm{ml}$ for the viruses studied.

\section{Results were compared between the RT-LAMP and other methods}

To illustrate the performance of the RT-LAMP assay, 638 NP swab specimens were tested, and these results were compared with those of commercial RT-PCR assay. Out of 638 samples, there have 93,5 , and 57 cases were detected as positive by the RT-LAMP primers of Universal, H1N1, and H3N2, respectively. In our study, we combined the results of Universal, H1N1, and H3N2 RT-LAMP for the diagnosis of influenza A virus, as long as one of them presented positive, it is judged as influenza A virus. Of these samples, 473 were detected as positive by the RT-PCR assays, and 439 were tested as positive by the RT-LAMP assays (Table 1). It is shown that detailed results of the RT-LAMP and RT-PCR on the viruses were studied. The agreement between these two methods was evaluated by $\kappa$ with a $95 \%$ CI for each virus, and all of them $\geq 0.85$. Compared to the RT-PCR, the results of the developed RT-LAMP assay showed excellent sensitivity and specificity.

To further demonstrate the advantages of RT-LAMP assay, 518 specimens were selected from the collection and tested for the antigens of Flu A and Flu B using commercial Colloidal Gold kit, only 85 and 131 were detected as Flu A and Flu B positive respectively (Table 2). In meeting the demand of rapid diagnosis, compared to the RT-PCR, we note that the $\kappa$ value of RT-LAMP for Flu A and Flu B were 0.875 and 0.918 respectively, while the values of the commercial Colloidal Gold kit were only 0.804 and 0.674 respectively. Also, the sensitivity of commercial Colloidal Gold kit was lower than the RT-LAMP, resulting in many positive specimens being missed.

\section{Sanger sequencing analyzed inconsistent samples between RT-LAMP assay and RT-PCR}

To further evaluate the diagnostic accuracy of the RT-LAMP assay, Sanger sequencing was performed on specimens with discordant results between RT-LAMP assay and RT-PCR. As shown in Table 3, compared with Sanger sequencing, the missed detection is present in both RT-PCR and RT-LAMP.

\section{Discussion}

There are many different viruses causing URTI in children with similar clinical symptoms, so it is difficult for clinicians to make an accurate diagnosis based on patients' symptoms. Current clinical methods for the diagnosis of ARD include viral isolation method, viral antigen detection, and nucleic acid detection. Viral isolation is still considered the "gold standard" and remains indispensable as a source for analyzing genetic in virus populations, but it cannot be applied for routine patient diagnostics for the vast majority of hospitals. The methods of viral antigen detection include fluorescentantibody assay (DFA) and immunochromatographic lateral flow assay (LFA). With the premise of ensuring the quality of specimens, the diagnostic value of DFA is as great as that of conventional virus isolation. The method also is limited by the availability of monoclonal antibodies for newly discovered viruses. Compared to DFA, LFA required simple techniques that could be applied to the routine procedure without special training, but low sensitivity is still a problem. Nucleic acid amplification techniques such as PCR with high sensitivity greatly increase the detection rate. However, most of them are based on real-time PCR which is not convenient for basic laboratories and community hospitals for the requirement of thermal cycle with real-time fluorescence measurement, strict experimental operation condition, highly trained personnel, and time-consuming.

Given the highly contagious and spreads quickly of respiratory infectious diseases, this study established a fast, simple, and sensitive RT-LAMP that applies to POCT to facilitate the detection of common viruses among ARD.

To ensure the stability of the detection assay, we aligned viruses based upon sequences deposited in databases and then selected conversed regions without gene mutations in the viruses studied, including matrix gene of Flu A; matrix gene of H1N1; hemagglutinin gene of H3N2; NS1 gene of Flu B; polymerase gene of RSV A; fusion glycoprotein gene of RSV B; hexon gene of HAdV; hemagglutinin gene of PIV1 and PIV3; and polyprotein gene of HRV. By the addition of loop forward (LF) and loop backward (LB) primers, the RT-LAMP assays could be accelerated, and the reaction times would be shortened. The temperature of $63^{\circ} \mathrm{C}$ and the $\mathrm{Mg}^{2+}$ concentration of $8 \mathrm{mM}$ were confirmed as the optimum condition for the RT-LAMP assay. Additionally, the 10 developed RT-LAMP assays have a high sensitivity, with a limit of detection of $1 \times 10^{2}$ copies $/ \mathrm{ml}$ per reaction, and show no cross-reactivity among the viruses studied. 

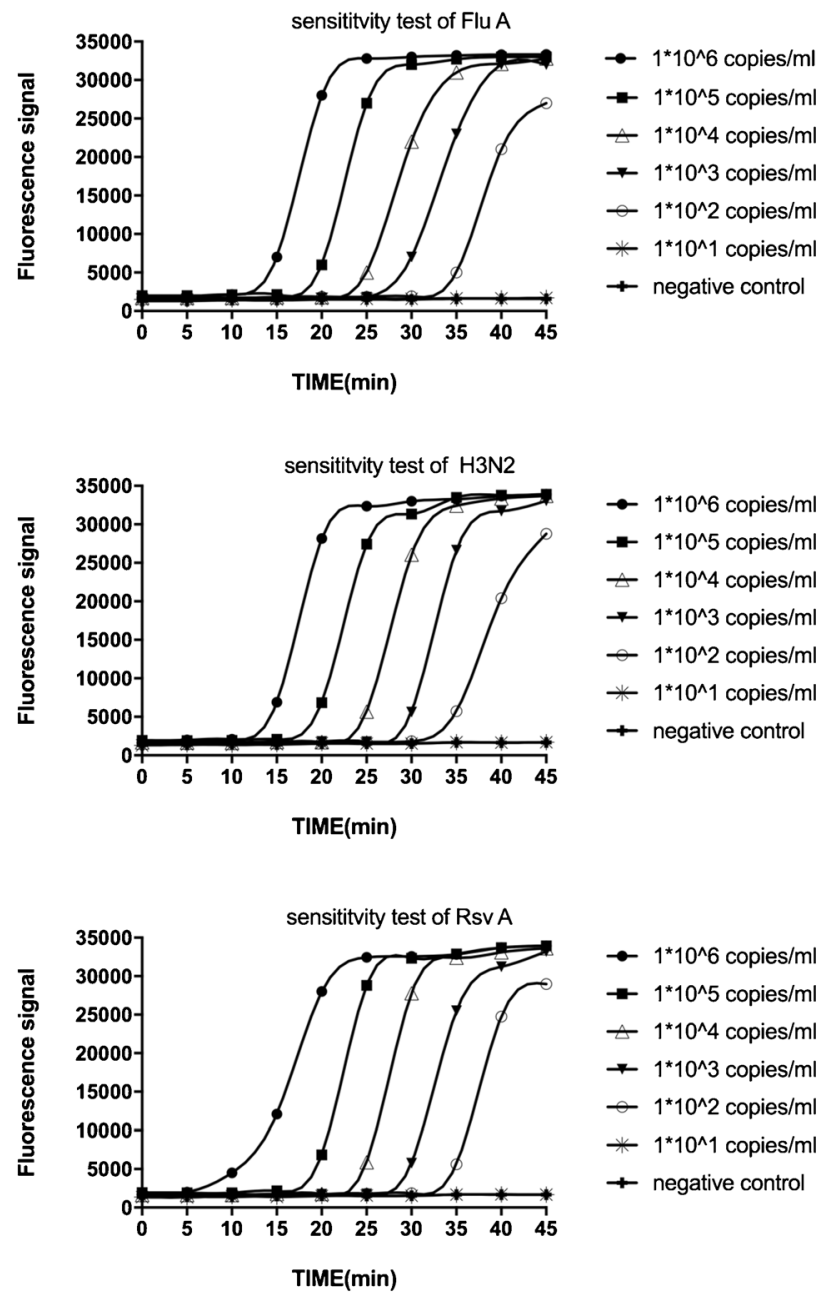

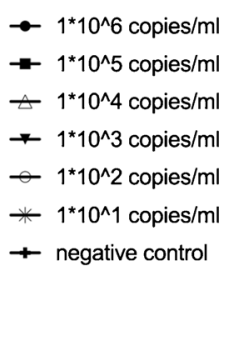
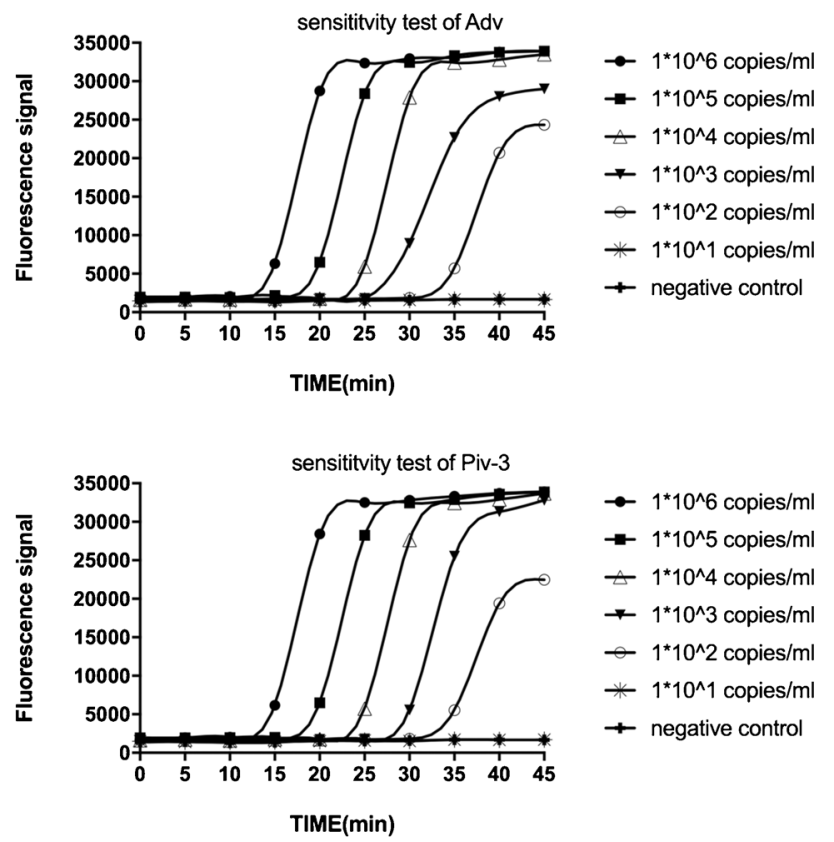
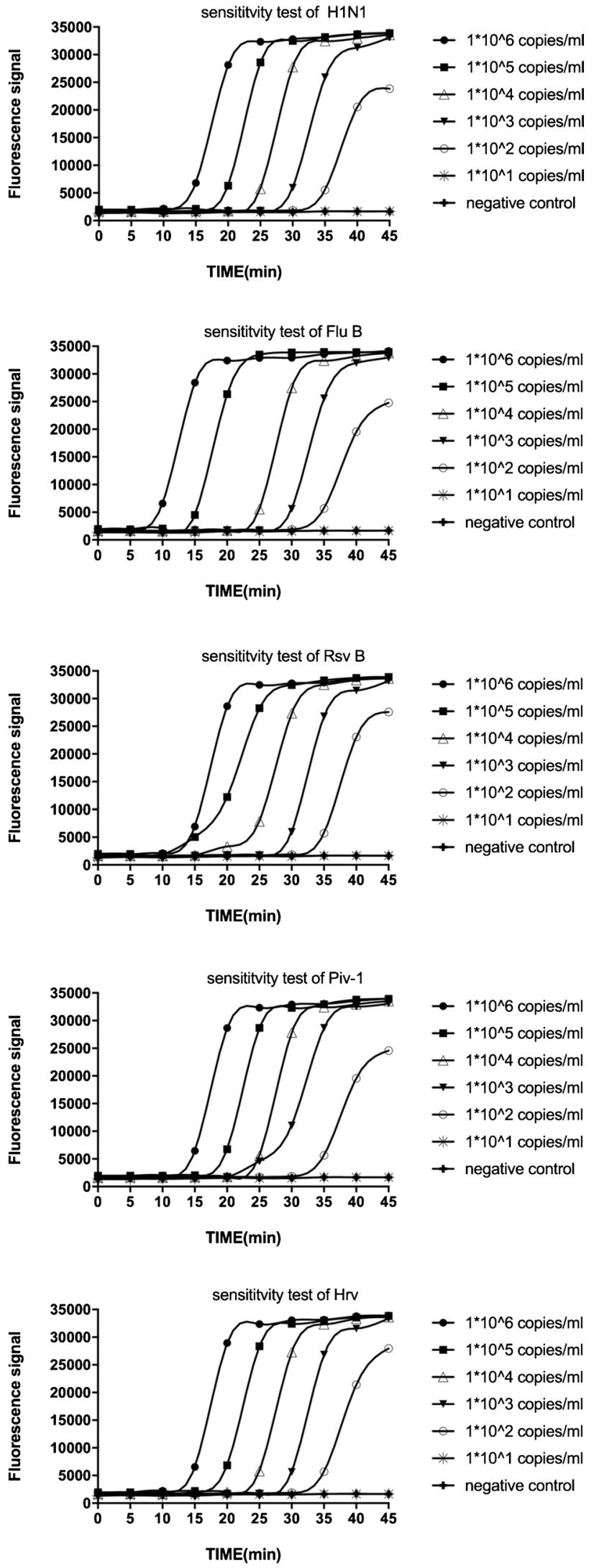

Fig. 4 Sensitivity for the RT-LAMP system. Sensitivity test results of the RT-LAMP using ten-fold serially diluted template, ranging from $1 \times 10^{6} \mathrm{copies} / \mathrm{ml}$ to $1 \times 10^{1} \mathrm{copies} / \mathrm{ml}$ 
Table 1 Comparison of the developed RT-LAMP assays with commercial RT-PCR assays

\begin{tabular}{|c|c|c|c|c|c|c|}
\hline \multirow[t]{2}{*}{ Types of virus } & \multirow[t]{2}{*}{ RT-PCR } & \multicolumn{2}{|l|}{ RT-LAMP } & \multirow[t]{2}{*}{ Subtotal } & \multirow[t]{2}{*}{ Kappa } & \multirow[t]{2}{*}{$\mathrm{P}$} \\
\hline & & + & - & & & \\
\hline \multirow[t]{3}{*}{ Flu A } & + & $101(86.32 \%)^{\mathrm{a}}$ & $16(13.68 \%)^{\mathrm{c}}$ & 117 & 0.881 & $\mathrm{P}<0.001$ \\
\hline & - & $6(1.15 \%)^{\mathrm{b}}$ & $515(98.85 \%)^{\mathrm{d}}$ & 521 & & \\
\hline & Subtotal & 107 & 531 & 638 & & \\
\hline \multirow[t]{3}{*}{ Flu B } & + & $189(91.30 \%)^{\mathrm{a}}$ & $18(8.70 \%)^{\mathrm{c}}$ & 207 & 0.931 & $\mathrm{P}<0.001$ \\
\hline & - & $1(0.23 \%)^{\mathrm{b}}$ & $430(99.77 \%)^{\mathrm{d}}$ & 431 & & \\
\hline & Subtotal & 190 & 448 & 638 & & \\
\hline \multirow[t]{3}{*}{ RSV A } & + & $2(100 \%)^{a}$ & $0(0 \%)^{\mathrm{c}}$ & 2 & 1.000 & $\mathrm{P}<0.001$ \\
\hline & - & $0(0 \%)^{b}$ & $636(100 \%)^{d}$ & 636 & & \\
\hline & Subtotal & 2 & 636 & 638 & & \\
\hline \multirow[t]{3}{*}{ RSV B } & + & $22(100 \%)^{\mathrm{a}}$ & $0(0 \%)^{\mathrm{c}}$ & 22 & 1.000 & $\mathrm{P}<0.001$ \\
\hline & - & $0(0 \%)^{\mathrm{b}}$ & $616(100 \%)^{\mathrm{d}}$ & 616 & & \\
\hline & Subtotal & 22 & 616 & 638 & & \\
\hline \multirow[t]{3}{*}{ HAdV } & + & $27(90.00 \%)^{\mathrm{a}}$ & $3(10.00 \%)^{\mathrm{c}}$ & 30 & 0.945 & $\mathrm{P}<0.001$ \\
\hline & - & $0(0 \%)^{\mathrm{b}}$ & $608(100 \%)^{\mathrm{d}}$ & 608 & & \\
\hline & Subtotal & 27 & 611 & 638 & & \\
\hline \multirow[t]{3}{*}{ PIV-1 } & + & $1(100 \%)^{\mathrm{a}}$ & $0(0 \%)^{\mathrm{c}}$ & 1 & 1.000 & $\mathrm{P}<0.001$ \\
\hline & - & $0(0 \%)^{\mathrm{b}}$ & $637(100 \%)^{\mathrm{d}}$ & 637 & & \\
\hline & Subtotal & 1 & 637 & 638 & & \\
\hline \multirow[t]{3}{*}{ PIV-3 } & + & $5(100 \%)^{\mathrm{a}}$ & $0(0 \%)^{\mathrm{c}}$ & 5 & 1.000 & $\mathrm{P}<0.001$ \\
\hline & - & $0(0 \%)^{\mathrm{b}}$ & $633(100 \%)^{\mathrm{d}}$ & 633 & & \\
\hline & Subtotal & 5 & 633 & 638 & & \\
\hline \multirow[t]{3}{*}{ HRV } & + & $87(98.86 \%)^{\mathrm{a}}$ & $1(1.14 \%)^{\mathrm{c}}$ & 88 & 0.993 & $\mathrm{P}<0.001$ \\
\hline & - & $0(0 \%)^{\mathrm{b}}$ & $550(100 \%)^{\mathrm{d}}$ & 550 & & \\
\hline & Subtotal & 87 & 551 & 638 & & \\
\hline
\end{tabular}

Notes: ${ }^{a}$ the rate of sensitivity or true positive rate, ${ }^{b}$ false-positive rate, ${ }^{c}$ false-negative rate, ${ }^{d}$ the rate of specificity or true negative rate

\begin{tabular}{|c|c|c|c|c|c|c|c|c|c|}
\hline \multirow[t]{3}{*}{ Diagnostic test } & & \multicolumn{4}{|c|}{ Influenza A virus } & \multicolumn{4}{|c|}{ Influenza B virus } \\
\hline & & \multicolumn{2}{|c|}{ RT-LAMP } & \multicolumn{2}{|c|}{ Colloidal Gold kit } & \multicolumn{2}{|c|}{ RT-LAMP } & \multicolumn{2}{|c|}{$\begin{array}{l}\text { Colloidal Gold } \\
\text { kit }\end{array}$} \\
\hline & & + & - & + & - & + & - & + & - \\
\hline \multirow[t]{2}{*}{ RT-PCR } & + & 101 & 16 & 85 & 32 & 188 & 19 & 131 & 76 \\
\hline & - & 6 & 395 & 0 & 401 & 1 & 310 & 0 & 311 \\
\hline Sensitivity & & 0.863 & & 0.726 & & 0.908 & & 0.633 & \\
\hline Specificity & & 0.985 & & 1 & & 0.997 & & 1 & \\
\hline Kappa & & 0.875 & & 0.804 & & 0.918 & & 0.674 & \\
\hline $\mathrm{P}$ & & $\mathrm{P}<0.001$ & & $\mathrm{P}<0.001$ & & $\mathrm{P}<0.001$ & & $\mathrm{P}<0.001$ & \\
\hline
\end{tabular}

Table 2 Results of RT-LAMP and a commercial Colloidal Gold kit, respectively, were compared to results using a commercial RT-PCR assay
To determine the clinical performance of the RT-LAMP assay, a total of $638 \mathrm{NP}$ swab samples were screened by RT-LAMP and RT-PCR simultaneously. The novel RTLAMP assay showed a high consistency (92.81\%) with a commercial RT-PCR assay for URTI detection. We evaluated the agreement between RT-PCR and RT-LAMP for each virus by the values of $\kappa$. The Kappa of all viruses were more than 0.85 revealed an excellent agreement between the two methods. All discordant results between
RT-LAMP assay and RT-PCR were illustrated by Sanger sequencing, compared to the results of RT-PCR; all negative samples detected by the novel RT-LAMP assay had high threshold cycle (CT) values $(>38)$ in the RT-PCR assay, indicating very low viral loads. Anyway, the results of the developed RT-LAMP assay revealed high sensitivity and specificity for studied viruses which suggests that the primers used in this assay are suitable for the rapid detection of respiratory viruses. It is sufficiently sensitive for 
Table 3 Sanger sequencing analyzed inconsistent samples between RT-LAMP assay and RT-PCR

\begin{tabular}{lllll}
\hline Types of virus & $\begin{array}{l}\text { RT-LAMP / } \\
\text { RT-PCR }\end{array}$ & \multicolumn{2}{l}{ Sanger sequencing } & \multirow{2}{*}{ Total } \\
\cline { 3 - 4 } & & + & - & \\
\hline Flu A & $-/+$ & 16 & 0 & 16 \\
& $+/-$ & 6 & 0 & 6 \\
Flu B & $-/+$ & 17 & 1 & 18 \\
& $+/-$ & 1 & 0 & 1 \\
HAdV & $-/+$ & 3 & 0 & 3 \\
HRV & $-/+$ & 1 & 0 & 1 \\
\hline
\end{tabular}

the detection of respiratory infectious diseases at an early stage of infection using NP specimens.

For influenza A and B viruses, we also evaluated the method of LFA by commercial kit. Compared with RT-PCR, only $85(72.65 \%)$ and 131 (63.29\%) were detected as Flu A and Flu B positive respectively; the method required less time to complete the detection, but resulting in a high falsenegative rate and missed detections. The data presented in this study suggested that the developed RT-LAMP assays are better than the commercial Colloidal Gold kit. It must be pointed out that the RT-LAMP can not only meet the needs of rapid diagnosis but also have high accuracy.

A total of $638 \mathrm{NP}$ swab specimens were collected between the winter of 2019 and 2020. Positive specimens for RSV, HAdv, and PIV were less frequent in this study. It is a limitation in our article. However, the SARS-CoV-2 broke out suddenly at the end of 2019. The number of patients with URTI caused by other viruses has decreased sharply. We have also made a great effort to contact other hospitals in the Shanghai area and found that there are relatively few patients with URTI in the region at this stage. Of course, we will continue to refine this work in the future.

In summary, we have developed an RT-LAMP platform that can be used to detect the majority of viruses among respiratory infectious diseases. It also performed high diagnostic sensitivity and specificity among clinical samples, so the RT-LAMP assay may be a powerful tool for URTI identification, especially during the dramatic increase in the number of patients. It is essential to control the outbreak and to select an appropriate treatment.

Supplementary Information The online version contains supplementary material available at https://doi.org/10.1007/s10096-021-04300-8.

Funding This work was supported by the project "Development of a High Throughput Assay for Respiratory Infection Viruses", funded by the Science and Technology Commission of Shanghai Municipality.
Data availability The datasets generated during and/or analyzed during the current study are available from the corresponding author on reasonable request.

\section{Declarations}

Ethics approval All the samples were residual specimens after diagnostic sampling therefore do not involve ethics approval.

Consent to participate Not applicable.

Consent for publication Not applicable.

Conflict of interest The authors declare no competing interests.

\section{References}

1. Nair H, Simões EA, Rudan I et al (2013) Global and regional burden of hospital admissions for severe acute lower respiratory infections in young children in 2010: a systematic analysis. Lancet 381(9875):1380-1390

2. Hung IF, Zhang AJ, To KK et al (2017) Unexpectedly higher morbidity and mortality of hospitalized elderly patients associated with rhinovirus compared with influenza virus respiratory tract infection. Int J Mol Sci 18(2)

3. Morens DM, Folkers GK, Fauci AS (2004) The challenge of emerging and re-emerging infectious diseases. Nature 430(6996):242-249

4. Falsey AR, Hennessey PA, Formica MA et al (2005) Respiratory syncytial virus infection in elderly and high-risk adults. N Engl J Med 352(17):1749-1759

5. Zhu N, Zhang D, Wang W et al (2020) A novel coronavirus from patients with pneumonia in China, 2019. N Engl J Med 382(8):727-733

6. Falsey AR, Criddle MC, Walsh EE (2006) Detection of respiratory syncytial virus and human metapneumovirus by reverse transcription polymerase chain reaction in adults with and without respiratory illness. J Clin Virol 35(1):46-50

7. Mahony JB (2008) Detection of respiratory viruses by molecular methods. Clin Microbiol Rev 21(4):716-747

8. Notomi T, Okayama H, Masubuchi H et al (2000) Loop-mediated isothermal amplification of DNA. Nucleic Acids Res 28(12):E63

9. Tomita N, Mori Y, Kanda H et al (2008) Loop-mediated isothermal amplification (LAMP) of gene sequences and simple visual detection of products. Nat Protoc 3(5):877-882

10. Nagamine K, Hase T, Notomi T (2002) Accelerated reaction by loop-mediated isothermal amplification using loop primers. Mol Cell Probes 16(3):223-229

Publisher's Note Springer Nature remains neutral with regard to jurisdictional claims in published maps and institutional affiliations. 